ISSN 2075-1729

www.mdpi.com/journal/life

\title{
Communication
}

\section{Supercritical Carbon Dioxide and Its Potential as a Life-Sustaining Solvent in a Planetary Environment}

\author{
Nediljko Budisa ${ }^{1, \dagger, *}$ and Dirk Schulze-Makuch ${ }^{2,3, \dagger, *}$ \\ 1 Department of Chemistry, Technical University Berlin, Müller-Breslau-Straße 10, \\ D-10623 Berlin, Germany
}

2 Center for Astronomy and Astrophysics, Technical University Berlin, Hardenbergstraße 36, D-10623 Berlin, Germany

3 School of the Environment, Washington State University, Pullman, WA 99164, USA

$\dagger$ Both authors contributed equally to this work.

* Authors to whom correspondence should be addressed; E-Mails: budisa@biocat.tu-berlin.de (N.B.); dirksm@wsu.edu (D.S.-M.); Tel.: +49-30-314-28-821 (N.B.); Fax: + 49-30-314-28-279 (N.B.).

Received: 25 June 2014; in revised form: 30 July 2014 / Accepted: 31 July 2014 /

Published: 8 August 2014

\begin{abstract}
Supercritical fluids have different properties compared to regular fluids and could play a role as life-sustaining solvents on other worlds. Even on Earth, some bacterial species have been shown to be tolerant to supercritical fluids. The special properties of supercritical fluids, which include various types of selectivities (e.g., stereo-, regio-, and chemo-selectivity) have recently been recognized in biotechnology and used to catalyze reactions that do not occur in water. One suitable example is enzymes when they are exposed to supercritical fluids such as supercritical carbon dioxide: enzymes become even more stable, because they are conformationally rigid in the dehydrated state. Furthermore, enzymes in anhydrous organic solvents exhibit a "molecular memory", i.e., the capacity to "remember" a conformational or $\mathrm{pH}$ state from being exposed to a previous solvent. Planetary environments with supercritical fluids, particularly supercritical carbon dioxide, exist, even on Earth (below the ocean floor), on Venus, and likely on Super-Earth type exoplanets. These planetary environments may present a possible habitat for exotic life.
\end{abstract}


Keywords: anhydrous solvents; biotransformations; carbon dioxide; enzymes; geochemistry; habitat; molecular memory; organic solvents; $\mathrm{scCO}_{2}$

\section{Supercritical $\mathrm{CO}_{2}$ and Its Special Properties as a Supercritical Fluid}

Supercritical fluids (SCFs) differ quite significantly compared to the properties of real fluids. For example, supercritical water is relatively non-polar and acidic [1]. Supercritical fluids cannot be defined as a liquid or as a gas but as a substance in a state ("supercritical state") above its critical temperature $\left(\mathrm{T}_{\mathrm{C}}\right)$ and critical pressure $\left(\mathrm{P}_{\mathrm{C}}\right)$. For example, supercritical carbon dioxide $\left(\mathrm{scCO}_{2}\right.$; critical point: $7.38 \mathrm{MPa}, 304 \mathrm{~K} / 31.1^{\circ} \mathrm{C}$ and 73.8 bar) is a nonpolar medium with large quadrupolar moment [2]. Its density can be changed as a function of temperature and pressure [3]. At critical pressure, its compressibility is maximized, and small changes to thermal parameters can lead to large changes in its local density (Figure 1).

Not surprisingly, SCFs as non-aqueous solvents for enzyme-catalyzed reactions have gained the attention of enzymologists since the 1980s and have been employed in a variety of biotechnological applications due to their numerous advantages [4]. Enzymes are not only able to function in SCFs but they also display interesting novel properties such as altered substrate specificity and enantio-selectivity, suppression of side-reactions, increased stability, and "molecular memory" [5]. In general, SCFs differ from ordinary solvents in having both liquid-like solubilizing capacities whereas retaining high diffusivities and low viscosities of the gas phase. Near the critical point, small changes in temperature or pressure lead to significant changes in solubility, partition coefficient, dipole moment and the dielectric constant. It is relatively easy to control these properties, because small changes in pressure or temperature near the critical point can alter the reactivity in biochemical processes as the solvent strength of a supercritical fluid can be varied by changing pressure and temperature [6].

The change in properties from subcritical fluid to supercritical state is especially noteworthy for the common compounds water and carbon dioxide. These include: (1) high solubility of gases within supercritical mixtures, (2) miscibility of gases such as $\mathrm{O}_{2}$ and $\mathrm{H}_{2}$ in supercritical fluids, (3) high diffusion rates and variable density, and (4) high dissolving power [1,7]. As a conclusion, Ikushima advanced the case for supercritical fluids as an appropriate medium for chemical and biochemical processes under certain conditions [6].

Here, we focus on supercritical carbon dioxide $\left(\mathrm{scCO}_{2}\right)$, which attracted particular attention in research and technology due to its "green" (i.e., sustainable) properties. $\mathrm{ScCO}_{2}$ is chemically relatively inert (for example, it is "immune" to free radical chemistry) and is a low-toxicity aprotic solvent [8]. Unlike water, $\mathrm{scCO}_{2}$ is an easily accessible supercritical regime $\left(7.38 \mathrm{MPa}, 304 \mathrm{~K} / 31.1^{\circ} \mathrm{C}\right.$ and 73.8 bar) and, as a solvent, is miscible with both fluorous and organic materials [9,10] (Figure 1). Also, carbon dioxide is at the maximum oxidation number of carbon (+IV; chemically fully oxidized state) and therefore is inert towards further oxidation (i.e., non-flammable). Supercritical carbon dioxide can thus serve as solvent for "difficult" chemical transformations, such as the direct reaction of hydrogen and oxygen to form hydrogen peroxide [11] or various selective free-radical reactions [3]. 
Figure 1. Schematic p-T phase diagram of $\mathrm{CO}_{2}$. Note if the temperature and pressure of a substance are both higher than Tc and Pc for a particular substance, the substance is defined as a supercritical fluid. Carbon dioxide has four distinct phases; the standard solid, liquid and gas phase as well as the supercritical phase. Carbon dioxide transitions to supercritical phase occur relatively readily at the critical points of $7.38 \mathrm{MPa}, 304 \mathrm{~K} / 31.1^{\circ} \mathrm{C}$ and $73.8 \mathrm{bar}$.

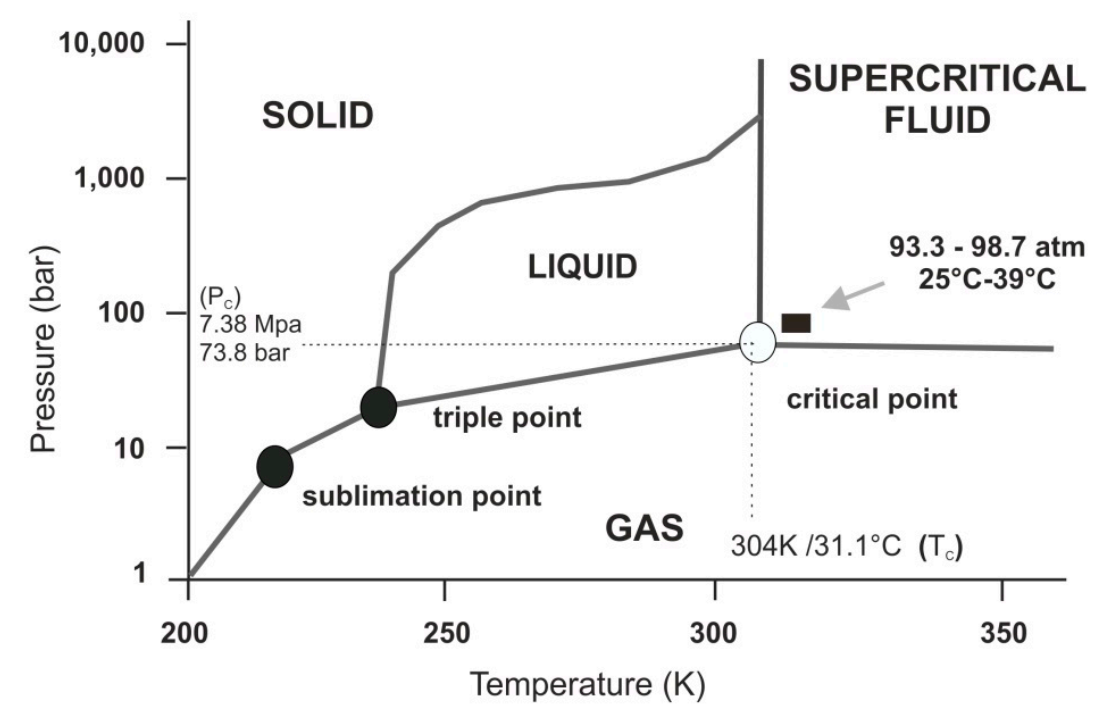

\section{Enzyme Activity in Anhydrous Organic Solvents Including $\mathrm{scCO}_{2}$}

Organic solvents are usually volatile carbon containing compounds present in liquid form at room temperature. On the other hand, supercritical fluids such as $\mathrm{scCO}_{2}$ can provide environments even more remote from water than organic solvents [12], but share many common features with organic solvents. Both represent a medium in which the vast majority of industrially-relevant biotechnological synthetic enzyme reactions take place as many water-insoluble substrates can be transformed by enzymes in non-aqueous media [13]. However, organic solvents are also extremely toxic for living cells, as they are capable of disrupting the cell membrane, which results in the leakage of macromolecules including RNA and proteins [14]. Curiously, organic-solvent-tolerant bacteria such as various Pseudomonas strains, especially Pseudomonas putida can withstand such harsh environments due to the presence of various adaptive mechanisms (e.g., they are able to change the chemical composition of their membranes, in addition to other adaptation techniques) $[15,16]$.

Enzymes of terrestrial organisms need a specific amount of bound water to be active [17]. The activity of a majority of enzymes is decreased upon transfer to non-aqueous solvents. The inactivation mechanism most probably include disruptive changes in the active site, blockage of substrate access, unfavorable substrate desolvation, and effects of transition state destabilization and restriction of conformational mobility [18]. In fact, enzymes in anhydrous environments are very rigid and through this property alone their activity is usually diminished. Water is needed for flexibility as a molecular lubricant and essential parts of the enzyme surface must be hydrated to allow catalysis to occur [19]. The three-dimensional structure of enzymes is dramatically altered under extremely dehydrating conditions, causing their denaturation and a consequent loss of their activity. However, if the conditions are less adverse, the protein structure may largely be retained. For example, $\mathrm{scCO}_{2}$ may dissolve from $0.3 \%$ to $0.5 \%(\mathrm{w} / \mathrm{w})$ water, depending on the pressure and temperature [20]. 
Kalibanov was among the first to realize that the water bound to the enzyme determines the catalytic activity rather than the total water content of the system [5]. In other words, the enzyme itself is "not interested" for more than a few water molecules or a small hydrate layer to develop optimal or even maximal activity. The optimum water content required for a particular biotransformation depends on the enzyme and the solvent [21]. Therefore, to maintain biocatalysis abilities in terrestrial organisms in adverse solvent environments such as $\mathrm{scCO}_{2}$ or any other non-aqueous media or supercritical fluids, it is of vital importance to have a minimum water content/solubility [22]. Completely dry enzymes are inactive - a threshold value of about $0.2 \mathrm{~g} \mathrm{H}_{2} \mathrm{O} / \mathrm{g}$ enzyme is generally accepted [23]. The role of this "structural" water is not only to maintain the enzyme's structure, but also to facilitate non-covalent bonding and disruption of hydrogen bonds during catalysis, which has a very significant influence on the reaction kinetics. On the other hand, minor structural changes may induce an alternative active protein state with altered enzyme activity, specificity and stability. For example, supercritical carbon dioxide as a solvent can accelerate mass-transfer of certain enzyme reactions [9].

A particularly notable feature of enzymes after being dissolved in an anhydrous apolar solvent and being in contact with a competitive inhibitor is the capacity to retain the state induced by the ligand (Figure 2). This phenomenon, known as ligand imprinting, bio-imprinting or ligand-induced enzyme memory, was first reported by Russell and Klibanov [24]. They observed that the activity of subtilisin in n-octane was enhanced when it was lyophilized from a solution containing competitive inhibitors (that were subsequently removed). It has been suggested that this kind of effect may be related to a "conformation memory" similar to the "pH memory" phenomenon seen in many enzymes [17]. That is, in organic solvents including $\mathrm{scCO}_{2}$, the catalytic activity of enzyme reflects (i.e., the enzyme "remembers") the $\mathrm{pH}$ (i.e., last ionization state) of last aqueous solution it was exposed to [12]. In this way, enzyme properties in a particular solvent are dependent on their history.

Figure 2. Effect of $\mathrm{scCO}_{2}$ as an anhydrous solvent on biochemical systems, specifically in regard to "enzyme memory". Lyophilization of enzymes (freeze-drying or cryo-desiccation) in organic solvents can enable enzymes to "remember" the exposure to a ligand-a phenomenon known as "ligand imprinting" or "ligand-induced enzyme memory" [12]. The induction of enzyme memory requires considerable conformational flexibility in the protein. High conformational rigidity present in nearly all anhydrous environments is the basic requirement for appearance and retention of "memory". For that reason, simple addition of smaller amounts of water is sufficient enough to erase the "memory" effect.

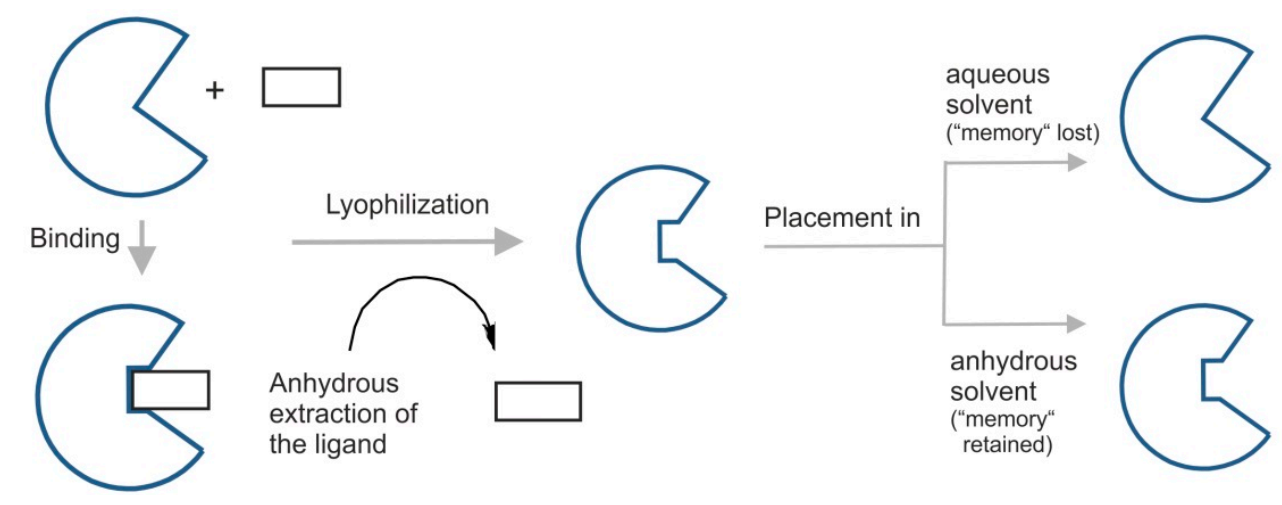




\section{Supercritical Carbon Dioxide in Biochemical Transformations}

The main advantages of $\mathrm{scCO}_{2}$ for biochemical transformations include increased catalytic activities as a result of improved mass transfer, higher selectivities and strong suppression of side reactions [6]. However, the low dielectric constant of $\mathrm{scCO}_{2}$ in the liquid state $(\approx 1.5)$ might require even higher pressures for certain classes of substances to be efficiently dissolved, whereas $\mathrm{scCO}_{2}$ as a Lewis acid is prone to react with chemical functional groups such as amines. Since enzyme surfaces are generally decorated lysine side chains, many free amine-groups are exposed to the solvent. These amine groups form carbamates with $\mathrm{CO}_{2}$ in a highly exothermic reaction [25]. The mechanism of $\mathrm{CO}_{2}$ reversible formation of carbonic acid is shown in Figure 3. The carbamates are stable at low temperatures. However, at higher temperatures $\mathrm{CO}_{2}$ is removed and amine function of lysine side chains is restored. Beside lysine residues, the imidazole side chain of histidine on the enzyme surface is also believed to have the capacity to participate in carbamoylation reaction [26]. In some cases, these reactions in $\mathrm{scCO}_{2}$ can lead to enzyme deactivation, whereas in some other instances, carbamate formation is believed to lead to changes in enzyme catalytic features (e.g., enhanced stereoselectivity). For example, Mase and co-workers speculated that a conformational change in enzyme due to carbamate formation provides good enantiomeric excess in lipase-catalyzed desymmetrization of 1,3-propanediacetate [27]. On the other hand, $\mathrm{scCO}_{2}$ can serve as a temporary protecting group in ruthenium-catalyzed metathesis as well as in rhodium-catalyzed hydroamino-methylations [23] and references cited therein.

Since $\mathrm{scCO}_{2}$ has the tendency to strip structurally relevant water (both external and internal) from the enzyme leading to deactivation, it is necessary to add a small amount of water to the substrates, which can reverse the deactivation and restore the enzyme activity. The preservation of the enzyme structure and optimal activity depend on the presence of small amounts of water in the supercritical dispersing medium. When the protein is at least partially hydrated, water molecules bind to specific sites on the enzyme surface and prevent carbon dioxide from penetrating into its catalytic core [4]. In this context, another property of $\mathrm{scCO}_{2}$ is that it can interfere with the catalytic activity of the enzyme by lowering the $\mathrm{pH}$ of the structural water (i.e., microaqueous environment or hydration layer associated with the enzyme) present in $\mathrm{scCO}_{2}$.

Major classes of enzymes used for biocatalytic synthesis in $\mathrm{scCO}_{2}$ are lipases, which are used for enantioselective (trans)-esterifications and esterifications of fatty acids. Some other enzymes used in $\mathrm{scCO}_{2}$ are thermolysin, several phosphatases, dehydrogenases, oxidases, amylases and decarboxylases for $\mathrm{CO}_{2}$-fixation [4]. As $\mathrm{scCO}_{2}$ exhibits a liquid-like density and a gas-like viscosity $\left(\mathrm{scCO}_{2}\right.$ liquid viscosity is only $1 / 10$ that of water [9]) any changes in the physical properties of supercritical $\mathrm{CO}_{2}$ by changing the pressure may induce an alternative active protein state with altered enzyme activity, specificity and stability [23]. The catalytic features of lipases in $\mathrm{scCO}_{2}$ are quite well understood: water and supercritical carbon dioxide coat the protein surface in a heterogeneous manner. Thereby, surface-exposed hydrophilic residues bind water, whereas carbon dioxide solvates surface-exposed hydrophobic residues (co-solvent effect). The substrate-binding region of the lipase is exposed to carbon dioxide, which facilitates diffusion of large apolar substrates (i.e., fatty acids) into active sites (hydrophobic tunnel), while preserving the functional structure of the enzyme [19]. Leitner pointed out that enzymes in $\mathrm{scCO}_{2}$ would not be considered analogous to an enzyme in solution, but rather behave as heterogeneous catalysts where diffusion of reactants in and out of the enzyme is not rate limiting [28]. 
Figure 3. Carbamate synthesis in reaction between $\mathrm{CO}_{2}$ and lysine side chains on the surface of an enzyme and the formation of carbonic acid and its dissociation to the bicarbonic anion in $\mathrm{scCO}_{2}[9]$.
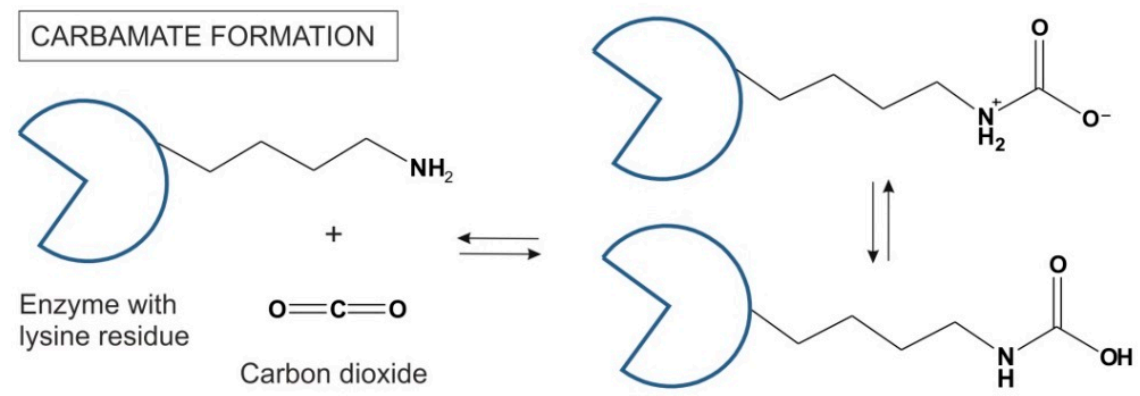

CARBONIC ACID FORMATION

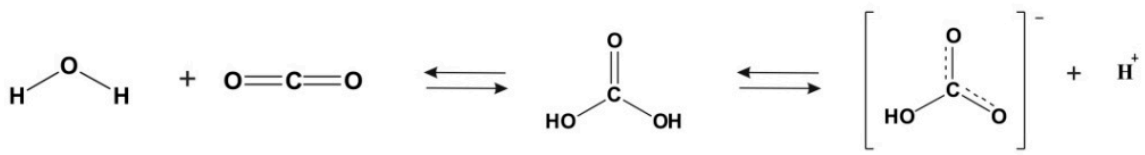

The majority of the reactions studied in $\mathrm{scCO}_{2}$ are hydrolytic reactions, which require the presence of catalytic traces of water ("catalytic water"). This certainly does not disqualify $\mathrm{scCO}_{2}$ as a potential solvent for life. For example, for nearly all oxidation-reduction reactions catalyzed by enzymes in water "catalytic amounts" of metals, either tightly bound to the enzyme or taken up from bulk solvent along with the substrate, are required. In fact, almost one-third of all known enzymes require one or more metal ions for catalytic activity, usually in order to catalyze certain reactions by reversible changes in the bound metal ion's redox state. The absolute necessity of traces of inorganic ions for enzymatic activity for so many enzymes in Earth's biochemistry certainly does not disqualify water as life solvent.

\section{Supercritical Carbon Dioxide, a Biological Agent?}

$\mathrm{ScCO}_{2}$ has a relatively low critical pressure and temperature [4] and is traditionally used as an alternative food-safety sterilization procedure/treatment, because it is a non-thermal process capable of inactivating microorganisms at relatively moderate pressures such as $7.3-50.0 \mathrm{MPa}$ at relatively low temperatures [29]. There is still no generally accepted view about the mechanism of the bactericidal activity of $\mathrm{scCO}_{2}$ [23], which may be related to pressure, temperature, and exposure time. For example, higher pressure enhances $\mathrm{CO}_{2}$ solubility and facilitates the acidification of the cellular interior [30]. On the other hand, $\mathrm{scCO}_{2}$ is believed to increase the fluidity of the cell membrane, enhancing its permeability and facilitate extraction of membrane components such as phospholipids [31]. This should not be surprising as the surface tension in carbon dioxide is much lower than that of water, whereas the diffusivity of solutes in $\mathrm{scCO}_{2}$ is markedly higher (low viscosity!). Thus, $\mathrm{scCO}_{2}$ can much easier penetrate complex molecular geometries and assemblies (e.g., cell membranes) than subcritical fluids can. Georgiou and Deamer have suggested supercritical fluid-mediated lipid extraction technology as the main method of choice in the search for biomarkers for extraterrestrial life. In particular, lipid-derived hydrocarbons as biomarkers must have a specific compositional pattern (e.g., odd/even 
number of carbon atoms in their chains, branching and unsaturation levels) that originates exclusively from biogenic processes [32].

On the other hand, $\mathrm{scCO}_{2}$ may be an appropriate medium for biochemical processes under certain conditions. Ikushima [6] reported the synthesis of esters from acryl donors and terpene alcohols by lipase in Candida cylindracea, which in supercritical carbon dioxide caused drastic conformational changes that enabled active sites to catalyze stereoselective synthesis. The reactivity was found to be susceptible to small changes in pressure or temperature near the critical point of the supercritical fluid. Shkrob and Sauer [33] showed that high mobility $\mathrm{CO}_{2}$-multimer anions in supercritical carbon dioxide form stable complexes with water, aliphatic alcohols, alkyl halides, and alkyl nitriles. Matsuda and co-workers have demonstrated that the alcohol dehydrogenase from Geotrichum candidum, active in $\mathrm{scCO}_{2}$ at $35{ }^{\circ} \mathrm{C}$ and $10 \mathrm{MPa}$ is capable of catalyzing the asymmetric reduction of various ketones [34]. The survival of the cells and preservation of enzyme activity under these conditions were explained by the water pool of the cytoplasm of cells in the resting state [35]. Through the solvent is in this case no longer $\mathrm{scCO}_{2}$, it shows that the application of $\mathrm{scCO}_{2}$ is not incompatible with life processes. Various enzymatic reactions were studied using bacterial species such as Bacillus megaterium, Geotrichum candidum or Aureobasidium pullulans (for detailed review see [23]).

An example of a planetary environment where supercritical $\mathrm{CO}_{2}$ might support living processes was reported by Schulze-Makuch and Irwin [7]. They pointed to the discovery of subsurface accumulations of liquid carbon dioxide under Earth's oceans [36]. The low density liquid $\mathrm{CO}_{2}$ has been found to be trapped by a surface rock layer and sub layer cap of $\mathrm{CO}_{2}$ hydrate $\left(\mathrm{CO}_{2} \times 6 \mathrm{H}_{2} \mathrm{O}\right)$. As the density of liquid $\mathrm{CO}_{2}$ increases with depth, it becomes denser than sea water, which opens up the possibility of many reservoirs of supercritical carbon dioxide on the sea floor [37]. Most intriguing was the detection of $10^{7}$ cells $/ \mathrm{ml}$ at the fluid $\mathrm{CO}_{2} / \mathrm{CO}_{2}$-hydrate interface [36], which is quite remarkable given the potentially hostile nature of $\mathrm{CO}_{2}$ [38]. Since $\mathrm{CO}_{2}$ is a very common compound in planetary atmospheres, including our neighboring planets Venus and $\mathrm{Mars}, \mathrm{scCO}_{2}$ is expected to occur in a variety of planetary environments.

One location where $\mathrm{CO}_{2}$ should occur in the supercritical state is in the near-subsurface of Venus. Venus is nearly as massive as Earth and has an atmosphere of 92 bar, which mostly consists of $\mathrm{CO}_{2}$. Thus, it would be a great natural laboratory for testing the properties of $\mathrm{scCO}_{2}$. An interesting twist is that Venus was located in the habitable zone of our Solar System in its early history. Schulze-Makuch and co-workers $[39,40]$ suggested the presence of an early biosphere on the surface of this planet, before a run-away greenhouse effect made all life near the Venusian surface all but impossible. However, perhaps some biomarkers from this earlier biosphere could have been preserved in the supercritical $\mathrm{CO}_{2}$. [32] The importance of $\mathrm{scCO}_{2}$ extends far beyond Venus though, since many of the detected exoplanets are Super-Earths, with 10 or more earth masses. All these high pressure environments are locations where we might expect $\mathrm{scCO}_{2}$, given its common occurrence. Certainly, $\mathrm{scCO}_{2}$ deserves more attention not only for its biochemical and biotechnological applicability, but also as potential life-sustaining solvent in exotic planetary environments. 


\section{Conclusions}

When we consider $\mathrm{scCO}_{2}$ as a potential life-sustaining medium, we need to free us from the classical anthropocentric approach that defines water as the exclusive and sole solvent of life. Doubtlessly, putative life on a planet with $\mathrm{scCO}_{2}$ alone or in a mixture with water (to various extents) would be based on a different biochemistry, including different organization of boundary conditions (membranes), metabolic pathways, informational and energy flows as well as different polymers with informational and catalytic functions. The problem of increased conformational rigidity of enzymes in $\mathrm{scCO}_{2}$, known from Earth's biochemistry, should not be taken dogmatically, particularly the notion that hyperthermophile proteins, due to enhanced conformational inflexibility in the folded native state, cannot achieve high enzyme activity (at lower temperatures) with a rigid active site(s) [41]. Proteins elsewhere might have a different composition other than the canonical 20 natural amino acids and the monomeric building blocks of enzymes might have a different backbone and side chain chemistries. Indeed, it is well documented that hyperthermophilic proteins are capable to perform extremely high catalytic activity (even at low temperature) that can salvage short-lived substrates or metabolically unstable intermediates in a rigid active site in the context of hyperstable protein scaffolds [41].

Therefore, carbon dioxide is not just a "greenhouse gas" but also an abundant molecule with many potential applications for life. In the supercritical phase, it is an aprotic solvent miscible with a variety of organic liquids and some bacteria and their enzymes are active in this solvent. Planetary environments with supercritical carbon dioxide exist under the seabed of the Earth, on Venus, and probably on exoplanets such as Super-Earths.

\section{Acknowledgments}

We are in debt to Patrick Durkin for a critical review of our manuscript.

\section{Author Contributions}

Nediljko Budisa wrote the first draft with the biochemically and biotechnologically relevant part of the manuscript, he also prepared graphic material. Dirk Schulze-Makuch wrote the first draft of the habitability and biologically relevant part of the manuscript. Both authors iterated with each other through later versions of the paper and approved the final manuscript.

\section{Conflicts of Interest}

The authors declare no conflict of interest.

\section{References}

1. National Research Council (NRC). The Limits of Organic Life in Planetary Systems; The National Academies Press: Washington, DC, USA, 2007; pp. 76-77.

2. Eckert, C.A. Supercritical fluids as solvents for chemical and materials processing. Nature 1996, 383, 313-318. 
3. Cormier, P.J.; Clarke, R.M.; McFadden, R.M.; Ghandi, K. Selective free radical reactions using supercritical carbon dioxide. J. Am. Chem. Soc. 2014, 136, 2200-2203.

4. Matsuda, T. Recent progress in biocatalysis using supercritical carbon dioxide. J. Biosci. Bioeng. 2013, 115, 233-241.

5. Klibanov, A.M. Enzyme memory - What is remembered and why? Nature 1995, 374, 596.

6. Ikushima, Y. Supercritical fluids: An interesting medium for chemical and biochemical processes. Adv. Colloid. Interface Sci. 1997, 71-72, 259-280.

7. Schulze-Makuch, D.; Irwin, L.N. Life in the Universe: Expectations and Constraints, 2nd ed.; Springer-Verlag: Berlin, Germany, 2008.

8. Mayadevi, S. Reactions in supercritical carbon dioxide. Indian J. Chem. 2012, 51, 1298-1305.

9. Beckman, E.J. Supercritical and near-critical $\mathrm{CO}_{2}$ in green chemical synthesis and processing. J. Supercrit. Fluid. 2004, 28, 121-191.

10. Budisa, N.; Kubyshkin, V.; Schulze-Makuch, D. Fluorine-rich planetary environments as possible habitats for life. Life 2014, in press.

11. Karmee, S.K.; Roosen, C.; Kohlmann, C.; Lütz, S.; Greiner, L.; Leitner, W. Chemo-enzymatic cascade oxidation in supercritical carbon dioxide/water biphasic media. Green Chem. 2009, 11, 1052-1055.

12. Klibanov, A.M. Improving enzymes by using them in organic solvents. Nature 2001, 409, 241-246.

13. Torres, S.; Castro, G.R. Non-aqueous biocatalysis in homogeneous solvent systems. Food Technol. Biotechnol. 2004, 42, 271-277.

14. Sardessai, Y.; Bhosle, S. Tolerance of bacteria to organic solvents. Res. Microbiol. 2002, 153, 263-268.

15. Torres, S.; Pandey, A.; Castro, G.R. Organic solvent adaptation of Gram positive bacteria: applications and biotechnological potentials. Biotechnol. Adv. 2011, 29, 442-452.

16. Segura, A.; Molina, L.; Fillet, S.; Krell, T.; Bernal, P.; Muñoz-Rojas, J.; Ramos, J.L. Solvent tolerance in Gram-negative bacteria. Curr. Opin. Biotechnol. 2012, 23, 415-421.

17. Gupta, M.N. Enzyme function in organic solvents. EJB Rev. 1993, 1992, 17-24.

18. De Bont, J.A.M. Solvent-tolerant bacteria in biocatalysis. Trends Tibtech. 1998, 16, 493-499.

19. Silveira, R.L.; Martínez, J.; Skaf, M.S.; Martínez, L.J. Enzyme microheterogeneous hydration and stabilization in supercritical carbon dioxide. J. Phys. Chem. B. 2012, 116, 5671-5678.

20. Oparin, R.; Tassaing, T.; Danten, Y.; Besnard, M. Water-carbon dioxide mixtures at high temperatures and pressures: Local order in the water rich phase investigated by vibrational spectroscopy. J. Chem. Phys. 2005, 123, 224501.

21. Yang, L.; Dordick, J.S.; Garde, S. Hydration of Enzyme in Nonaqueous Media is Consistent with Solvent Dependence of its Activity. Biophys. J. 2004, 87, 812-821.

22. De Gonzalo, G.; Lavandera, I.; Faber, K.; Kroutil, W. Enzymatic reduction of ketones in "micro-aqueous" media catalyzed by ADH-A from Rhodococcus ruber. Org. Lett. 2007, 9, 2163-2166.

23. Hobbs, H.R.; Thomas, N.R. Biocatalysis in supercritical fluids, in fluorous solvents, and under solvent-free conditions. Chem. Rev. 2007, 107, 2786-2820.

24. Russell, A.J.; Klibanov, A.M. Inhibitor-induced enzyme activation in organic solvents. J. Biol. Chem. 1988, 263, 11624-11626. 
25. Wright, H.B.; Moore, M.B. Reactions of Aralkyl Amines with Carbon Dioxide. J. Am. Chem. Soc. 1948, 70, 3865-3866.

26. Kamat, S.; Critchley, G.; Beckman, E.J.; Russell, A.J. Biocatalytic synthesis of acrylates in organic solvents and supercritical fluids: III. Does carbon dioxide covalently modify enzymes? Biotechnol. Bioeng. 1995, 46, 610-620.

27. Mase, N.; Sako, T.; Horikawa, Y.; Takabe, K. Novel strategic lipase-catalyzed asymmetrization of 1,3-propanediacetate in supercritical carbon dioxide. Tetrahedron Lett. 2003, 44, 5175-5178.

28. Leitner, W. Supercritical carbon dioxide as a green reaction medium for catalysis. Acc. Chem. Res. 2002, 35, 746-756.

29. Brunner, G. Applications of Supercritical Fluids. Annu. Rev. Chem. Biomol. Eng. 2010, 1, 321-342.

30. Rezaei, K.; Temelli, F.; Jenab, E. Effects of pressure and temperature on enzymatic reactions in supercritical fluids. Biotechnol. Adv. 2007, 25, 272-280.

31. White, A.; Burns, D.; Christensen, T.W. Effective terminal sterilization using supercritical carbon dioxide. J. Biotechnol. 2006, 123, 504-515.

32. Georgiou, C.D.; Deamer, D.W. Lipids as universal biomarkers of extraterrestrial life. Astrobiology 2014, 14, 541-549.

33. Shkrob, I.A.; Sauer, M.C. Solvent Anions in Supercritical Carbon Dioxide: Formation of Complexes with Polar Solutes. J. Phys. Chem. B 2001, 105, 7027-7032.

34. Matsuda, T.; Harada, T.; Nakamura, K. Alcohol dehydrogenase is active in supercritical carbon dioxide. Chem. Commun. 2000, 15, 1367-1368.

35. Matsuda, T.; Watanabe, K.; Harada, T.; Nakamura, K. Enzymatic reactions in supercritical $\mathrm{CO}_{2}$ : Carboxylation, asymmetric reduction and esterification. Catal. Today 2004, 96, 103-111.

36. Inagaki, F.; Kuypers, M.M.M.; Tsunogai, U.; Ishibashi, J.-I.; Nakamura, K.-I.; Treude, T.; Ohkubo, S.; Nakaseama, M.; Gena, K.; Chiba, H.; et al. Microbial community in a sediment-hosted $\mathrm{CO}_{2}$ lake of the southern Okinawa through hydrothermal system. Proc. Natl. Acad. Sci. USA 2006, 103, 14164-14169.

37. House, K.Z.; Schrag, D.P.; Harvey, C.F.; Lackner, K.S. Permanent carbon dioxide storage in deep-sea sediments. Proc. Natl. Acad. Sci. USA 2006, 103, 12291-12295.

38. Nealson, K. Lakes of liquid $\mathrm{CO}_{2}$ in the deep sea. Proc. Natl. Acad. Sci. USA 2006, 103, 13903-13904.

39. Schulze-Makuch, D.; Grinspoon, D.H.; Abbas, O.; Irwin, L.N.; Bullock, M.A. A sulfur-based UV adaptation strategy for putative phototrophic life in the Venusian atmosphere. Astrobiology 2004, 4, 11-18.

40. Schulze-Makuch, D.; Irwin, L.N.; Fairén, A.G. Drastic environmental change and its effects on a planetary biosphere. Icarus 2013, 225, 775-780.

41. Jaenicke, R. Do ultrastable proteins from hyperthermophiles have high or low conformational rigidity? Proc. Natl. Acad. Sci. USA 2000, 97, 2962-2964.

(C) 2014 by the authors; licensee MDPI, Basel, Switzerland. This article is an open access article distributed under the terms and conditions of the Creative Commons Attribution license (http://creativecommons.org/licenses/by/3.0/). 